\title{
Immediate and Lasting Effect of Cryoflow (IR Guided) on Pain in Patients with Frozen Shoulder: An Interventional Study
}

\author{
Manmitkaur A. Gill ${ }^{1}$, Neela C. Soni ${ }^{2}$ \\ ${ }^{1} \mathrm{PhD}$ Scholar, Gujarat University, MPT (Orthopaedics), Senior Lecturer, Department of Physiotherapy, \\ Government Spine Institute and Physiotherapy College, Civil Hospital Campus, Ahmedabad- 380016, Gujarat, \\ India. \\ ${ }^{2}$ MPT, PhD, Academic Director, SKUM College of Physiotherapy, Ahmedabad.
}

Corresponding Author: Manmitkaur A. Gill

\begin{abstract}
Background: Frozen shoulder is a painful and debilitating condition with an occurrence of $3 \%$ to $5 \%$ in the general population and up to $20 \%$ in those with diabetes. Physiotherapy has been established to be very effective in treatment of frozen shoulder. "Cryoflow IR machine is the first cryotherapy apparatus for cooling down free surrounding air with a biofeedback system, thereby it ensures a steady temperature on a treated area". Hence, this study was conducted to study the immediate and lasting effect of Cryoflow (IR guided) on pain in patients with frozen shoulder.

Aims and Objectives: To study an immediate and lasting effect of Cryoflow (IR guided) on pain in patients with frozen shoulder.

Methodology: 15 patients of frozen shoulder were included by convenience sampling after taking ethical approval for the present study. The patients were given Cryoflow (IR guided) for 10 minutes. Study Duration was of 1 month. Pre and post interventional outcome measures in terms of VAS score at rest and during activity were evaluated immediately and after 24 hours of treatment.

Results: Patients showed significant improvement when pre and post data were analyzed for VAS score at rest and during activity. $(\mathrm{p}<0.05)$.

Conclusion: Cryoflow (IR guided) has significant immediate and lasting effect (after $24 \mathrm{hrs}$ ) on pain at rest and on activity in patients with frozen shoulder.
\end{abstract}

Keywords: Frozen shoulder, Pain, Cryoflow (IR guided).

\section{INTRODUCTION}

Frozen shoulder is a painful and debilitating condition with an occurrence of $3 \%$ to $5 \%$ in the general population and up to $20 \%$ in those with diabetes. ${ }^{(1)}$ The term "frozen shoulder" was first introduced by Codman in 1934. The same condition had already been considered "peri-arthritis" by Duplay in 1872. In 1945, Nevasier coined the term "frozen shoulder" ${ }^{(1)}$ It is defined as self limiting condition and patients generally complain of an inability to sleep on the affected side. There is restricted glenohumeral elevation and external rotation. ${ }^{(2)}$ Cold application is one of the most extensively used treatment" Cryoflow IR device is the first cryotherapy apparatus for cooling down free surrounding air with a biofeedback system, thereby it ensures a steady temperature on a treated spot". The unique IR sensor monitors the skin temperature and auto regulates the airflow in order to keep the perfect and selected temperature constant. (3) "Cryotherapy is recommended to be used for local anesthesia (analgesia) for pain relief and rehabilitation, motor effects to improve mobility and for anti-inflammation by a 
combination of cold and compression with powerful cold airflow." ${ }^{(3)}$ Several studies have proved the effect of various electrotherapeutic modalities on pain in patients with frozen shoulder, but there are very few studies done on effect of Cryoflow (IR guided) on pain in patients with frozen shoulder. Hence, this study was conducted to see the immediate and lasting effect of cryoflow on pain in patients with frozen shoulder.

\section{AIMS:}

To study the effect of Cryoflow (IR guided) on pain in patients with frozen shoulder.

\section{OBJECTIVES:}

$>$ To study the immediate effect of Cryoflow (IR guided) on pain in patients with frozen shoulder.

$>$ To study the lasting effect of Cryoflow (IR guided)on pain in patients with frozen shoulder.

\section{METHODOLOGY}

The Patients suffering from frozen shoulder and those who are referred to physiotherapy department from Orthopaedic OPD and coming to physiotherapy department on OPD basis were selected according to inclusion and exclusion criteria for this interventional study. All the patients were informed about the nature and purpose of the study. Written informed consent was taken from all the patients in their understandable language. Inclusion criteria for the present study were- Patients who were diagnosed with frozen shoulder, Age group: 40-60 years, both male and female, patients who were willing to participate in the study. Exclusion criteria were kept as Patient with rotator cuff tear and other shoulder ligament injuries, Malignancy, Recent fracture in and around shoulder, any neurological disorder, Cervical radiculopathy and/or any Contraindication to Cryoflow (IR guided) application. After approval of ethical committee, 15 patients suffering from frozen shoulder were selected as per inclusion and exclusion criteria by using convenience sampling technique for the interventional study of 1 month duration. Assessment in terms of Visual analog scale ratings of pain severity (VAS score) at rest and on activity (VAS score) were taken at pre, post and after 24 hrs of Cryoflow (IR guided) application.Patients received treatment which included Cryoflow (IR guided) for 10 minutes- 14 degree Celsius temperature .Size of Nozzle was of $15 \mathrm{~mm}$ according to Cryoflow (IR guided manual).

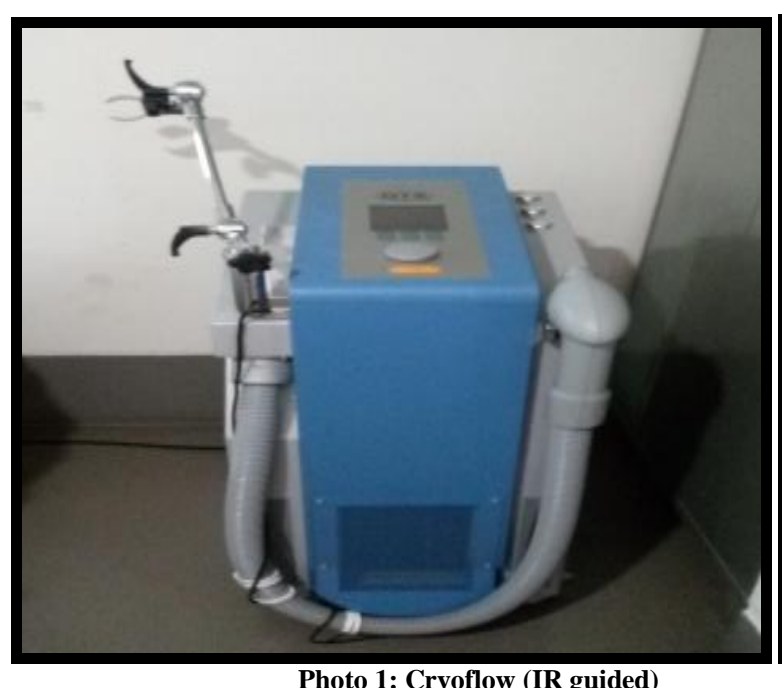

Photo 1: Cryoflow (IR guided)

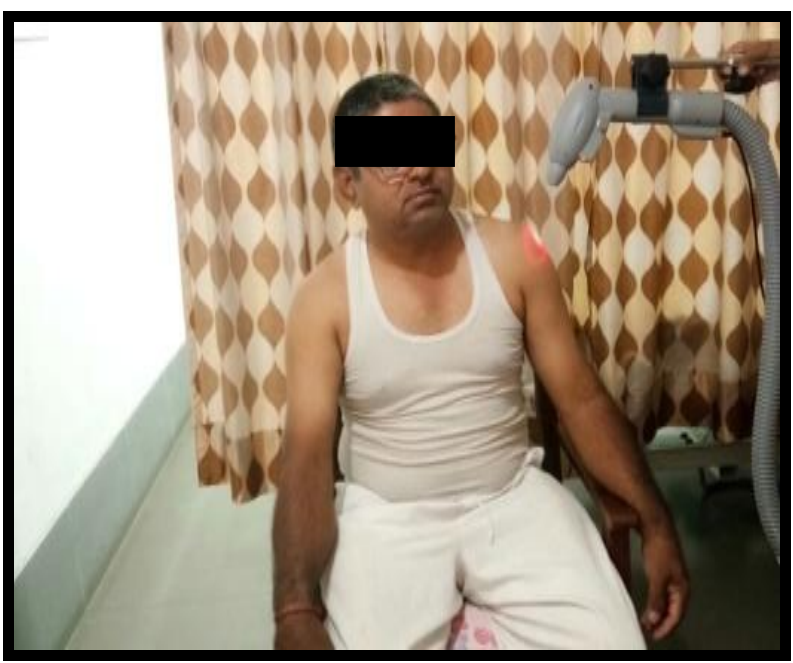

Photo 2: Patient receiving treatment

\section{RESULT}

Data of 15 patients were analysed with SPSS SOFTWARE VERSION 16.0.Level of significance was kept at $5 \%$ and confidence interval of $95 \%$.To analyse the immediate and 
Manmitkaur A. Gill et.al. Immediate and lasting effect of cryoflow (IR guided) on pain in patients with frozen shoulder: an interventional study.

lasting effect (after 24 hours) of VAS score at rest and on activity, Paired $\mathrm{T}$ test was used.

Table 1: Analysis of Pre and Post VAS score At Rest

\begin{tabular}{|l|l|l|l|l|l|}
\hline TAS (ON REST) & PRE SCORE & POST SCORE & t VALUE & P VALUE & SIGNIFICANCE \\
\hline IMMEDIATE EFFECT & $1.7 \pm 1.98$ & $1.06 \pm 1.43$ & 3.56 & 0.003 & SIGNIFICANT \\
\hline LASTING EFFECT $(24 \mathrm{hrs})$ & $1.7 \pm 1.98$ & $0.60 \pm 0.98$ & 3.69 & 0.002 & SIGNIFICANT \\
\hline
\end{tabular}

Table 2: Analysis of Pre and Post VAS score On Activity

Table 2: Analysis of Pre and Post VAS score On Activity
\begin{tabular}{|l|l|l|l|l|l|}
\hline VAS (ON ACTIVITY) & PRE SCORE & POST SCORE & t VALUE & P VALUE & SIGNIFICANCE \\
\hline IMMEDIATE EFFECT & $6.4 \pm 1.12$ & $4.5 \pm 1.3$ & 9.72 & 0.00 & SIGNIFICANT \\
\hline LASTING EFFECT (24 hrs) & $6.4 \pm 1.12$ & $3.9 \pm 1.22$ & 8.48 & 0.00 & SIGNIFICANT \\
\hline
\end{tabular}

\section{DISSCUSSION}

The purpose of this study was to study the immediate and lasting effect of Cryoflow (IR guided) on pain in patients with frozen shoulder. There is significant immediate and lasting effect (24hours) of Cryoflow (IR guided) on pain at rest and on activity in patients with frozen shoulder. Ranjan R et al (2013) did study on 30 patients(male 17, female 13) with age group 20-50 years and medically diagnosed shoulder impingement syndrome. They were randomized into either of two treatment groups, where 1 group were treated by cryoflow along with supervised exercise program and other were treated with supervised exercise only. The treatment was given to both groups for five days per week for two weeks. The result of this study showed that Cryoflow (IR guided) along with supervised exercise program is more effective shortterm treatment for shoulder impingement syndrome. Salah Eldin et al (2015) studied the effectiveness of cryoflow therapy on pain and function in induced muscle soreness on elbow flexors (non-dominant) . They concluded that cryoflow therapy is better in reducing delayed onset muscle soreness than the use of cryogel pack. The application of cold at frequent intervals produce an analgesic effect on the parts of the body treated (Bierman, 1955).

\section{CONCLUSION}

The present study concludes that Cryoflow (IR guided) has significant immediate and lasting effect (after $24 \mathrm{hrs}$ ) on pain at rest and on activity in patients with frozen shoulder.

\section{Acknowledgement: None}

\section{Conflict of Interest: None}

\section{Source of Funding: None}

Ethical Approval: Ethical committee approval was taken prior to the study.

\section{REFERENCES}

1. Phil page, Andre Labbe. Frozen shoulder: Use the evidence to integrate your interventions. North American Journal of Sports Physical Therapy, 2010.

2. Reeves B; The natural history of the frozen shoulder syndrome. Scand J Rheumatol. 1975;4(4):193-6.

3. Ranjan $\mathrm{R}$ et al. The effect of Cryoflow (IR guided) as a component of comprehensive treatment in shoulder pain. JODMSE 2013.

4. Salah Eldin B Elsayed et at. Efficacy of cryoflow therapy in induced muscle soreness: Randomized Trial. Bulletin of Faculty of Physical Therapy 2015; 20 (2).

5. Bierman W. Therapeutic use of cold. JAMA1955.157: 1189-2.

How to cite this article: Gill MA, Soni NC. Immediate and lasting effect of cryoflow (IR guided) on pain in patients with frozen shoulder: an interventional study. Int $J$ Health Sci Res. 2021; 11(8): 45-47. DOI: https://doi.org/10. 52403/ijhsr.20210807 